\title{
Severe Traumatic Brain Injury with Sphenopalatine Artery Ruptured: Case Report and Review of the Literature
}

\author{
Adil Belhachmi ${ }^{1,2}$, Yao Christian Hugues Dokponou1,2*\# ${ }^{1}$, Fernand Nathan Imoumby ${ }^{1,2} \oplus^{(}$, \\ Napoléon Imbunhe ${ }^{1,2}$, Sofia El Akroud1,2, Miloudi Gazzaz ${ }^{1,2}$ \\ ${ }^{1}$ Mohammed V University, Rabat, Morocco \\ ${ }^{2}$ Service de Neurochirurgie Hôpital Militaire d'Instruction Mohammed V, Rabat, Maroc \\ Email: abelhachmi510@gmail.com, "dokponou2407@gmail.com, ifernandnathan@gmail.com, imbunhe@gmail.com, \\ sofiaelakroud16@gmail.com, miloudigazzaz29@gmail.com
}

How to cite this paper: Belhachmi, A., Dokponou, Y.C.H., Imoumby, F.N., Imbunhe, N., El Akroud, S. and Gazzaz, M. (2021) Severe Traumatic Brain Injury with Sphenopalatine Artery Ruptured: Case Report and Review of the Literature. Open Journal of Modern Neurosurgery, 11, 204-209. https://doi.org/10.4236/ojmn.2021.113024

Received: May 11, 2021

Accepted: July 20, 2021

Published: July 23, 2021

Copyright () 2021 by author(s) and Scientific Research Publishing Inc. This work is licensed under the Creative Commons Attribution International License (CC BY 4.0).

http://creativecommons.org/licenses/by/4.0/ (c) (i) Open Access

\begin{abstract}
Emergency endovascular procedure for external carotid exclusion is required to save patients with life-threatening massive epistaxis from a ruptured sphenopalatine artery secondary to severe traumatic brain injury. We report a case of a 20 -year-old pedestrian admitted with a severe traumatic brain injury (TBI) secondary to an automobile (a lorry) road accident at high velocity. $\mathrm{He}$ presented to the emergency room in a coma with a Glasgow coma scale of $6 / 15$ and massive epistaxis. He underwent emergency stabilization by sedation and was intubated. Body CT-Scan shows fracture of the palatine and pterygoid plate and multiple fractures of the skull with intracranial right frontal lobe hematoma. CT-Angiography was done immediately and confirmed a rupture of the sphenopalatine artery. The patient died of massive epistaxis while waiting for the endovascular procedure. This is a rare clinical case that needs unusual emergency endovascular management. Arterial embolization in emergency settings should be thought in front of any patient with persistent post-traumatic nose bleeding and be carried out as soon as possible to save the patient's life.
\end{abstract}

\section{Keywords}

Traumatic Brain Injury, Sphenopalatine Artery, Endovascular

\section{Introduction}

Epistaxis or nasal hemorrhage is a frequent reason for patients seeking emer-

${ }^{\star}$ Joint first author.

${ }^{*}$ Corresponding author. 
gency medical care. The causes can be local, systemic, traumatic, environmental, drug-induced, or idiopathic. There are two types of nosebleeds: anterior (more common), and posterior (less common, but more likely to require medical attention). The source of $90 \%$ of anterior nosebleeds lies within Kiesselbach's plexus (also known as Little's area) on the anterior nasal septum. They are all capable of causing a simple tiny nosebleed as well as life-threatening massive bleeding [1].

After blunt or penetrating head and neck trauma, cerebral injuries often lead to significant disability from ischemic stroke, hemorrhagic stroke, and uncontrolled extracranial hemorrhage. Trauma causes carotid or vertebral dissection, occlusion, pseudoaneurysm, arteriovenous fistula, vessel transaction, traumatic epistaxis, venous sinus thrombosis, and carotid-cavernous fistula [2]. Apart from the danger of potential airway compromise, severe hemorrhage from branches of the carotid artery causing hemorrhagic shock can occur. Blind techniques, such as packing or ligation of external carotid arteries, are the usual methods to stop the bleeding [3]. With the advent of angiography and interventional radiology and cardiology, indirect visualization of vessels and control of bleeding at distant sites have become feasible [4].

We report the case of a 20-year-old patient victim of a severe traumatic brain injury (TBI), who presented to the emergency room in a coma with a Glasgow coma scale of $6 / 15$ and massive epistaxis.

\section{Case Presentation}

A 20-year-old man was admitted to the intensive care unit (ICU) with massive epistaxis on a severe traumatic brain injury (TBI) secondary to an automobile (a lorry) road accident at high velocity. He presented to the emergency room in a coma with a Glasgow coma scale of 6/15 and bilateral ecchymosis without rhinorrhea. He underwent emergency stabilization by sedation and was intubated. The patient's past medical history was unremarkable.

Body CT-Scan shows fracture of the palatine and pterygoid plate, as well as multiple fractures of the skull (right frontal bone, left temporal and parietal bone) intracranial left frontal lobe hematoma with intraventricular hemorrhage (Figure 1). CT-Angiography was done immediately and show extending spontaneous hyperdensity around the ophtalmo-sphenopalatine junction, confirming a rupture of the sphenopalatine artery (Figure 2).

The management of this case needs urgent arterial embolization to occlude the ruptured sphenopalatine artery thus, stopping the massive epistaxis. Despite nasal packing, which cannot help in this case, to stop the bleeding, the patient died before the endovascular procedure.

\section{Discussion}

Initial treatment priorities for patients with maxillofacial injuries and severe associated oronasal bleeding are not different from any other traumatic patient- 


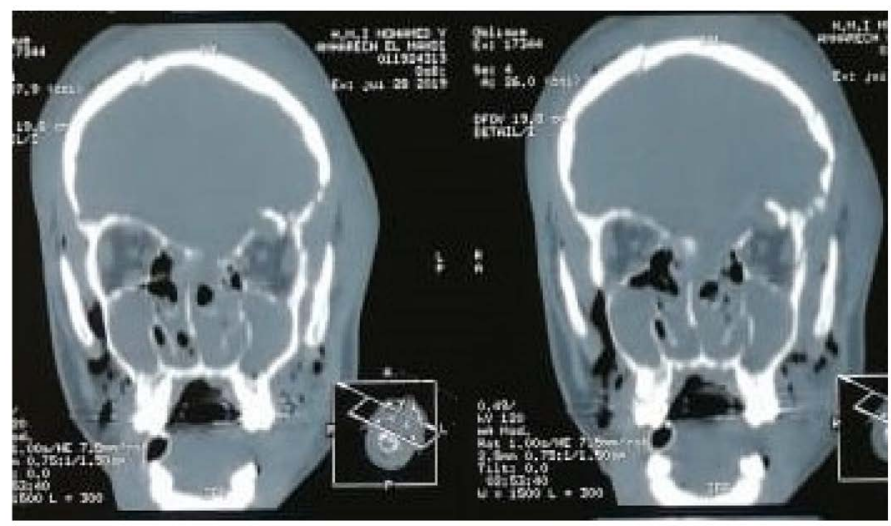

(a)

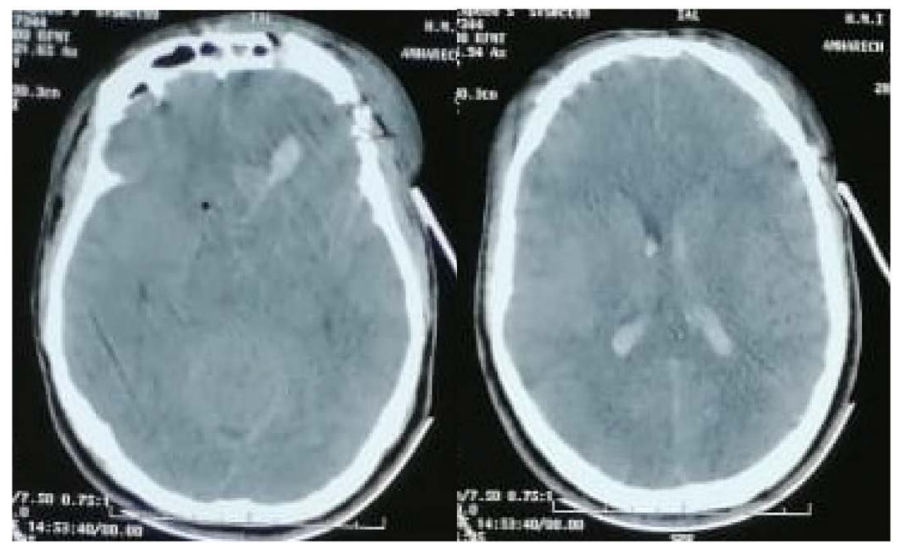

(b)

Figure 1. Brain CT-Scan showing: (a) Bone window with multiple fracture of skull and skull base; (b) Parenchymal window with left frontal hematoma and ventricular hemorrhage. Diffuse brain edema.

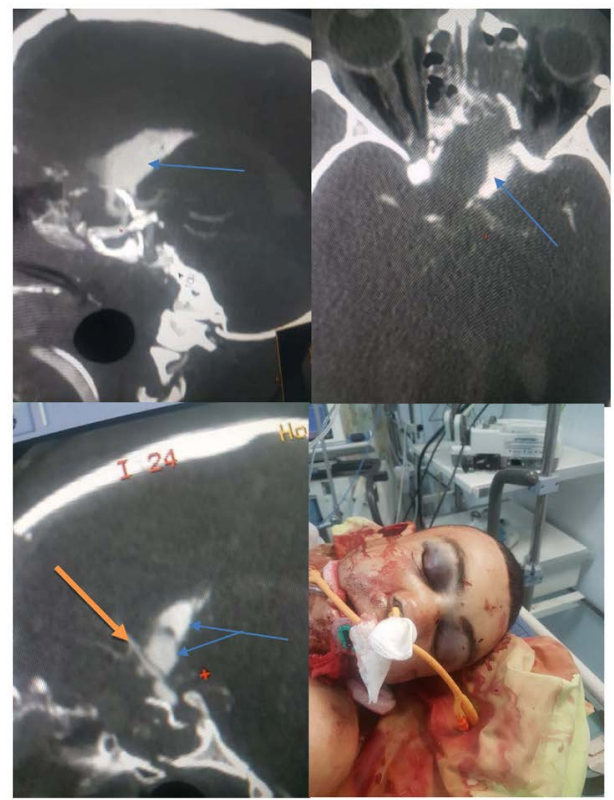

Figure 2. CT-angiography, Ophthalmic artery (Green arrow), Bleeding from the sphenopalatine artery (Blue arrow). 
airway, ventilation, and management of shock, including hemorrhage control, are the gold standard for their management. However, establishing a secure airway may be very challenging because of soft tissue disruption, swelling, unstable facial fractures, and ongoing hemorrhage [5]. Orotracheal intubation is the mainstay of airway management in patients with nasal hemorrhage. The nasotracheal route should be avoided. If tissue injury, edema, or bleeding precludes oral intubation, a surgical airway technique (cricothyroidotomy or emergency tracheostomy) should be used instead [5] [6]. Our patient underwent emergency stabilization and was intubated using the orotracheal route. As is the case for our patient, bleeding from the posterior or superior nasal cavity is often termed a posterior nosebleed. This is usually presumed due to bleeding from Woodruff's plexus, which are the posterior and superior terminal branches of the sphenopalatine and posterior ethmoidal arteries. These are often difficult to control and are associated with bleeding from both nostrils or into the nasopharynx. It can generate a greater flow of blood into the posterior pharynx and have a higher risk for airway compromise or aspiration due to increased difficulty in controlling the bleed. Hemorrhagic shock was demonstrated to occur in $24 \%$ of severe blunt maxillofacial injury patients [3] [7].

Oronasal hemorrhage from venous origin or minor arterial vessels due to severe TBI followed by maxillofacial trauma can often be managed efficiently with packing. However, if bleeding persists and threatened the patient's life, vessel ligation and arterial embolization are treatment options [6] [8] [9]. Cerebral angiography can help to identify the site of the bleeding, abnormal circulation, aneurysms, and arteriovenous malformations. As hemostatic control is better if embolic materials can target the peripheral vessels [4] [10], with fewer complications, superselective embolization of the ipsilateral sphenopalatine artery is performed on the laterality of the bleed. Mahadevia et al. have observed that most cases of intractable epistaxis have diffuse, bilateral mucosal congestion and hypervascularity on catheter angiography with no identifiable source of bleeding [4] [11]. Their study has recommended superselective bilateral embolization in cases of intractable epistaxis. The rationale is finding generalized hyperemia, poor localization of the bleeding vessel, and cross-circulation leading to recurrence of bleeding.

Embolization should be performed as close to the bleeding point as possible to avoid complications such as cranial nerve palsies. Also, superselective distal embolization may not stop the bleeding more rapidly than proximal embolization, leaving the risk of recurrent bleeding from anastomotic channels distal to the embolization site [9]. As sustained by Tsui et al., the immediate availability of an experienced interventional radiologist, related human resources, and facilities are the crucial determinants of success. The idea of having an interventional radiologist participating in a trauma team as a second-tier specialist should be considered [3]. This case would have met a better outcome.

To date, there are no specific and codify management pathways for the emergency treatment for the massive bleeding from the posterior and superior ter- 
minal branches of the sphenopalatine and posterior ethmoidal arteries. A systematic review and meta-analysis of all indicated available papers in the literature need to be done for details about this issue.

\section{Conclusion}

The urgent management of massive epistaxis secondary to severe traumatic brain injury with rupture sphenopalatine artery is a challenging issue that needs a rapid embolization of the bleeding artery. The diagnosis can be confirmed by CT-angiography.

\section{Conflicts of Interest}

The authors declare not having any conflict of interest in this case report and there are no financial resources.

\section{Author Contributions}

Yao Christian Hugues Dokponou: Conceptualization, Writing an original draft, \& editing. Adil Belhachmi: Writing an original draft, \& editing. Fernand Nathan Imoumby: Writing-review \& editing. Imbunhe Napoléon: Writing \& editing. El Akroud Sofia: Writing \& editing. Miloudi Gazzaz: Supervision, review, \& Validation.

\section{Ethics and Reporting Guidelines}

Informed consent and verbal permission were obtained from the patient's family prior to the submission of this article. Also, this article respects both the Consensus-based Clinical Case Reporting Guideline and the Recommendations for the Conducting, Reporting, Editing, and Publication of Scholarly Work in Medical Journals [12] [13].

\section{References}

[1] Tabassom, A. and Cho, J.J. (2021) Epistaxis. StatPearls Publishing, Treasure Island, FL. http://www.ncbi.nlm.nih.gov/books/NBK435997/

[2] Alderazi, Y.J., Cruz, G.M., Kass-Hout, T., Prestigiacomo, C.J., Duffis, E.J. and Gandhi, C.D. (2015) Endovascular Therapy for Cerebrovascular Injuries after Head and Neck Trauma. Trauma, 7, 258-269. https://doi.org/10.1177/1460408615573884

[3] Tsui, K.L., Yau, H.H. and Kam, C.W. (2002) Case Report: Life Threatening Bleeding Following Maxillofacial Injury. Hong Kong Journal of Emergency Medicine, 9, 42-45. https://doi.org/10.1177/102490790200900107

[4] Poduval, J., Arokiaraj, M.C., Bhat, V. and Savery, N. (2013) Bilateral Sphenopalatine Artery Embolisation in Panfacial Fractures-A Case Report. International Journal of Collaborative Research on Internal Medicine \& Public Health, 5, 0-0.

[5] Cogbill, T.H., Cothren, C.C., Ahearn, M.K., Cullinane, D.C., Kaups, K.L., Scalea, T.M., et al. (2008) Management of Maxillofacial Injuries with Severe Oronasal Hemorrhage: A Multicenter Perspective. Journal of Trauma and Acute Care Surgery, 65, 994-999. https://doi.org/10.1097/TA.0b013e318184ce12

[6] Conto, F. de, Siqueira, S., Colaco, J., Tonietto, L., Annes, R.D. and Vanzin, J.R. 
(2018) Arterial Embolization in the Treatment of Severe Epistaxis: A Case Report. International Journal of Odontostomatology, 12, 343-347. https://doi.org/10.4067/S0718-381X2018000400343

[7] Sakamoto, T., Yagi, K., Hiraide, A., Takasu, A., Kinoshita, Y., Iwai, A., et al. (1988) Transcatheter Embolization in the Treatment of Massive Bleeding Due to Maxillofacial Injury. Journal of Trauma, 28, 840-843. https://doi.org/10.1097/00005373-198806000-00022

[8] Wu, S.-C., Chen, R.-J., Lee, K.-W., Tung, C.-C., Lin, W.-P. and Yi, P. (2007) Angioembolization as an Effective Alternative for Hemostasis in Intractable Life-Threatening Maxillofacial Trauma Hemorrhage: Case Study. American Journal of Emergency Medicine, 25, 988-e1. https://doi.org/10.1016/j.ajem.2007.02.039

[9] Kurata, A., Kitahara, T., Miyasaka, Y., Ohwada, T., Yada, K. and Kan, S. (1993) Superselective Embolization for Severe Traumatic Epistaxis Caused by Fracture of the Skull Base. American Journal of Neuroradiology, 14, 343-345.

[10] Kakizawa, H., Toyota, N., Naito, A. and Ito, K. (2005) Endovascular Therapy for Management of Oral Hemorrhage in Malignant Head and Neck Tumors. Cardio Vascular and Interventional Radiology, 28, 722-779. https://doi.org/10.1007/s00270-004-0130-5

[11] Mahadevia, A.A., Murphy, K.J., Obray, R. and Gailloud, P. (2005) Embolization for Intractable Epistaxis. Techniques in Vascular and Interventional Radiology, 8, 134-138. https://doi.org/10.1053/j.tvir.2005.10.006

[12] Gagnier, J.J., Kienle, G., Altman, D.G., Moher, D., Sox, H., Riley, D., et al. (2013) The CARE Guidelines: Consensus-Based Clinical Case Reporting Guideline Development. Deutsches Ärzteblatt International, 110, 603-608. https://doi.org/10.3238/arztebl.2013.0603

[13] Editors IC of MJ (2019) Recommendations for the Conducting, Reporting, Editing, and Publication of Scholarly Work in Medical Journals. ICMJE. http://www.icmje.org/icmje-recommendations.pdf 